Rev. Bras. Saúde Prod. Anim., Salvador, v.17, n.3, p.438-447 jul./set., $2016 \quad$ http://www.rbspa.ufba.br

\title{
Relação treonina: lisina digestíveis na dieta de poedeiras leves de 42 a 58 semanas de idade
}

Digestible threonine: lysine ratio in diets for white laying hens at 42 to 58 weeks of age

\author{
PASTORE, Silvana Marques ${ }^{1 *}$; ALBINO, Luiz Fernando Teixeira ${ }^{1}$; GOMES, Paulo \\ Cezar $^{1}$; OLIVEIRA, Will Pereira de ${ }^{2}$; SILVA, Eliane Aparecida da ${ }^{1}$; VIANA, Gabriel \\ da Silva ${ }^{1}$; MENDES, Melissa Fabíola dos Santos Alves ${ }^{1}$; ALVES, Warley Junior ${ }^{1}$; \\ IGLESIAS, Erick ${ }^{1}$
}

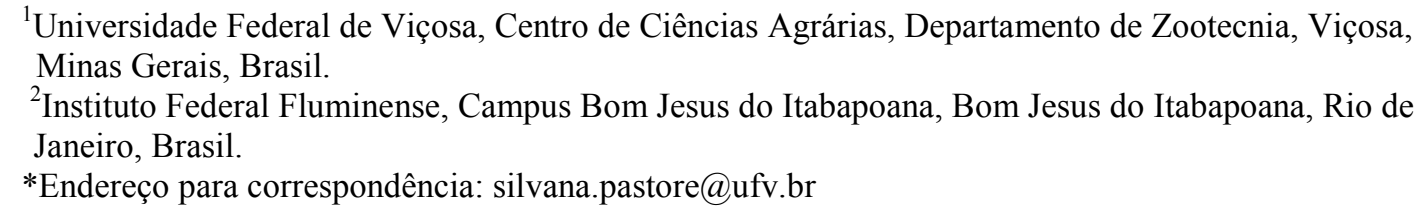

\section{RESUMO}

Este estudo foi realizado para determinar a relação ideal de treonina:lisina digestíveis para poedeiras leves no período de 42 a 58 semanas de idade. Foram utilizadas 240 poedeiras Hy Line W-36 com 42 semanas de idade durante 16 semanas. Os tratamentos foram distribuídos em delineamento inteiramente casualizado, com oito repetições e seis aves por unidade experimental. As dietas experimentais foram formuladas com cinco níveis de treonina digestível $(0,461 ; 0,515 ; 0,569 ; 0,622$ e $0,676 \%$ ) proporcionando as cinco relações treonina:lisina digestíveis $(60 ; 67 ; 74 ; 81$ e $88 \%)$ estudadas. As variáveis analisadas foram: produção de ovos; consumo de ração, de lisina e de treonina; massa e peso médio dos ovos; eficiências de utilização da lisina por massa e ovos produzidos; conversões alimentares por massa e dúzia de ovos; pesos médios de: gema, albúmen e de casca; ganho de peso; peso corporal final das aves; e balanço de nitrogênio. As relações treonina:lisina digestíveis na dieta não influenciaram as variáveis analisadas, exceto o consumo de treonina que apresentou efeito linear. A relação ideal de treonina:lisina digestíveis na dieta para galinhas poedeiras leves de 42 a 58 semanas de idade é de $60 \%$, que corresponde ao nível de $0,461 \%$ de treonina digestível na dieta e ao consumo diário de treonina digestível de 446mg/ave.

Palavras-chave: aminoácido, desempenho, galinhas, qualidade de ovo

\section{SUMMARY}

This study was conducted to determine the ideal ratio of digestible threonine: lysine in diets for laying hens at 42 to 58 weeks of age. Two hundred forty Hy Line W-36 laying hens were used at 42 weeks of age for 16 weeks. The treatments were distributed in a completely randomized design with eight replicates and six birds each. The experimental diets were formulated with five levels of digestible threonine $(0.461 ; 0.515 ; 0.569$; 0.622 and $0.676 \%$ ) providing the five ratio of digestible threonine: lysine $(60 ; 67 ; 74 ; 81$ and $88 \%)$ studied. The variables analyzed were: egg production; feed intake; lysine intake; threonine intake; mass egg; average egg weight; lysine use efficiencies by mass and produced eggs; feed conversion per mass and dozen eggs; Average weights yolk, albumen and shell; weight gain and final body weights of birds; and nitrogen balance. The digestible threonine: lysine ratio in the diet did not influence the analyzed variables except consumption of threonine which showed a linear effect. The ideal ratio of digestible threonine: lysine in diets for white laying hens at 42 to 58 weeks of age is $60 \%$, which corresponds to the level of $0.461 \%$ of digestible threonine in the diet and daily intake of digestible threonine $446 \mathrm{mg} /$ bird.

Keywords: amino acid, performance, hens, egg quality 


\section{INTRODUÇÃO}

As galinhas poedeiras comerciais possuem elevada capacidade produtiva, com produção de cerca de 430 ovos/ciclo (HY LINE W36, 2015). Todavia, essas aves necessitam do fornecimento de nutrientes em quantidades adequadas, inclusive aminoácidos, para a produção de ovos em níveis compatíveis ao seu potencial genético.

Com o intuito de atender as necessidades de aminoácidos dessas galinhas poedeiras tem sido empregado o conceito de proteína ideal na formulação das dietas. $\mathrm{O}$ conceito de proteína ideal visa fornecer a quantidade exata de aminoácidos para otimizar o desempenho dos animais, e devem ser expressos como proporções ideais com a lisina e em relação ao consumo de ração diário. Dessa forma, busca-se melhorar os índices produtivos e reduzir a excreção de nitrogênio pelas aves.

$\mathrm{O}$ fornecimento da relação ideal treonina:lisina digestíveis nas dietas favorece a absorção e o uso fisiológico da treonina pelas aves. Isso ocorre porque a treonina compõe o perfil aminoacídico da proteína ideal e também é o principal componente das mucinas intestinas, além de está envolvida na produção de anticorpos (LELIS, 2010). Esse aminoácido ainda participa da formação da proteína muscular e manutenção do turnover proteico corporal, além de participar da formação do colágeno (SÁ et al., 2007).

A treonina é um aminoácido essencial para aves, sendo considerado o terceiro aminoácido limitante nas dietas a base de milho e farelo de soja para poedeiras comerciais. Pesquisas buscando determinar a relação ideal da treonina:lisina digestíveis para poedeiras tem gerado resultados norteadores, mas não conclusivos. Rocha (2010) propõe a relação treonina:lisina digestíveis de $65 \%$ para poedeiras leves de 42 a 58 semanas de idade. Em estudos com poedeiras semipesadas de 42 a 54 semanas de idade, Lelis (2010) determinou a relação ideal de treonina:lisina digestíveis de $72 \%$. Entretanto, Rostagno et al. (2011) recomendam a relação treonina:lisina digestíveis de $76 \%$ para poedeiras leves com massa de ovos de $51 \mathrm{~g}$.

Sendo assim, este estudo foi realizado com o objetivo de determinar a relação ideal de treonina:lisina digestíveis em dietas formuladas com o conceito de proteína ideal para poedeiras leves no período de 42 a 58 semanas de idade.

\section{MATERIAL E MÉTODOS}

O experimento foi realizado no Setor de Avicultura do Departamento de Zootecnia da Universidade Federal de Viçosa-MG, sua condução foi aprovada pela Comissão de Ética no Uso de Animais de Produção da Universidade Federal de Viçosa sob o protocolo $\mathrm{n}^{\circ}$ 24/2014 e teve duração de 16 semanas. Foram utilizadas 240 poedeiras Hy-Line W36 com 42 semanas de idade, peso inicial de $1,460 \pm 0,06 \mathrm{~kg}$ e taxa de postura média de $88,3 \%$ no início do período experimental. Os tratamentos foram distribuídos em delineamento inteiramente casualizado, com oito repetições e seis aves por unidade experimental.

A unidade experimental foi constituída de uma gaiola com três divisórias de 25 $\mathrm{x} 40 \mathrm{x} 45 \mathrm{~cm}$. As aves foram alojadas aos pares nas gaiolas (densidade de $500 \mathrm{~cm}^{2} /$ ave) equipadas com bebedouro tipo nipple e comedouro tipo calha galvanizada. As gaiolas encontravam-se no galpão de postura, com dimensões de 12 x 8m, fechado nas laterais com tela antipássaros e coberto com telha de barro. 
A distribuição das poedeiras nas unidades experimentais foi realizada utilizando-se como critérios de padronização o peso corporal e a taxa de postura. O controle da produção de ovos foi realizado no período de 40 a 42 semanas de idade, de modo a permitir a uniformização das aves pela taxa de postura antes do arraçoamento com as dietas experimentais.

Ao completarem 42 semanas de idade, as poedeiras passaram a receber a dieta experimental pertinente a cada tratamento (Tabela 1), todas isoenergéticas $\mathrm{e}$ isonutritivas, exceto para treonina. $\mathrm{Na}$ formulação das dietas experimentais foi usado um nível subótimo de lisina digestível $(0,768 \%), \quad 10 \%$ a menos daquele preconizado por Rostagno et al. (2011), corrigido para o consumo médio diário de $95 \mathrm{~g}$ /ave de ração.

As dietas experimentais foram formuladas com cinco níveis de treonina digestível $(0,461 ; 0,515 ; 0,569 ; 0,622 \mathrm{e}$ $0,676 \%$ proporcionando as cinco relações treonina:lisina digestíveis $(60$; $67 ; 74 ; 81$ e $88 \%$ ) que foram avaliadas. $\mathrm{Na}$ formulação das rações considerou-se o teor de proteína bruta e a energia dos aminoácidos incorporados às rações, conforme proposto por Rostagno et al. (2011). Assim, para manter constante o nível de proteína bruta e energia das dietas foram usado L-glutâmico e o inerte.

Em cada nível de suplementação foi mantida as relações dos aminoácidos essenciais com a lisina de no mínimo $103 ; 28 ; 76 ; 96 ; 103 ; 152 ; 44$ e $137 \%$ para metionina + cistina; triptofano; isoleucina; valina; arginina; leucina; histidina e fenilalanina + tirosina, respectivamente.

As relações de metionina + cistina; triptofano; isoleucina e valina com a lisina ficaram três pontos percentuais acima daquelas determinadas, respectivamente, por Brumano et al. (2010), Calderano et al. (2012), Melo et al. (2012) e Almeida (2014). As demais relações mencionadas ficaram no mínimo três pontos percentuais acima do preconizado por Rostagno et al. (2011). O balanço eletrolítico das dietas (BED) experimentais foi calculado segundo Mongin (1980) utilizando-se a fórmula: $\mathrm{N}^{\circ}$ de Mongin $(\mathrm{NM})=\mathrm{mEqNa}^{+}+$ $\mathrm{mEqK}^{+}-\mathrm{mEqCl}^{-}(\mathrm{mEq} / \mathrm{kg})$. $\mathrm{O}$ cálculo do $\mathrm{NM}$ foi realizado considerando-se os valores percentuais dos eletrólitos, por meio da seguinte fórmula: $\mathrm{NM}=\% \mathrm{Na}^{+} \mathrm{x}$ $10.000 / 22,990 *+\% \mathrm{~K}^{+} \times 10.000 / 39,102 *$ - $\% \mathrm{Cl}^{-} \times 10.000 / 35,453 *$ (*equivalente grama do $\mathrm{Na}, \mathrm{K} \mathrm{e} \mathrm{Cl}$, respectivamente).

Os demais nutrientes contidos nas dietas, exceto os níveis de proteína bruta e treonina, atenderam as recomendações estabelecidas por Rostagno et al. (2011). Para o cálculo das dietas foi considerado o consumo médio diário de ração de $95 \mathrm{~g} /$ ave.

As dietas foram fornecidas diariamente às $8 \mathrm{~h}$ e às 16h, garantindo às aves consumo de ração e água à vontade durante todo o período experimental.

O programa de luz adotado foi de $17 \mathrm{~h}$ de luz diárias. $\mathrm{O}$ controle do fornecimento de luz foi realizado por meio de um temporizador digital.

A variação da temperatura do ar no interior do galpão foi registrada diariamente às $16 \mathrm{~h}$, por meio de dois termômetros de máxima e mínima, distribuídos em pontos distintos do galpão, posicionados à altura das aves.

O período experimental foi subdividido em quatro subperíodos de 28 dias, encerrando-se quando as aves completaram 58 semanas de idade. Ao final de cada subperíodo, as sobras de ração dos comedouros e dos baldes foram pesadas e o consumo de ração foi mensurado. $\mathrm{O}$ consumo de treonina e de lisina foi mensurado multiplicando o consumo de ração pela concentração, respectivamente, de treonina e de lisina de cada dieta. A produção de ovos foi registrada diariamente. 
Rev. Bras. Saúde Prod. Anim., Salvador, v.17, n.3, p.438-447 jul./set., $2016 \quad \underline{\text { http://www.rbspa.ufba.br }}$ ISSN 15199940

Tabela 1. Composição e valor nutricional das rações experimentais

\begin{tabular}{|c|c|c|c|c|c|}
\hline \multirow{2}{*}{ Ingredientes $(\%)$} & \multicolumn{5}{|c|}{ Relação treonina digestível:lisina digestível (\%) } \\
\hline & 60 & 67 & 74 & 81 & 88 \\
\hline Milho & 65,793 & 65,793 & 65,793 & 65,793 & 65,793 \\
\hline Farelo de soja (45\%) & 18,034 & 18,034 & 18,034 & 18,034 & 18,034 \\
\hline Calcário & 10,226 & 10,226 & 10,226 & 10,226 & 10,226 \\
\hline Óleo de soja & 2,405 & 2,405 & 2,405 & 2,405 & 2,405 \\
\hline Fosfato bicálcico & 1,280 & 1,280 & 1,280 & 1,280 & 1,280 \\
\hline Sal comum & 0,555 & 0,555 & 0,555 & 0,555 & 0,555 \\
\hline Carbonato de potássio & 0,161 & 0,161 & 0,161 & 0,161 & 0,161 \\
\hline Cloreto de colina $(60 \%)$ & 0,020 & 0,020 & 0,020 & 0,020 & 0,020 \\
\hline Mistura vitamínica $^{1}$ & 0,100 & 0,100 & 0,100 & 0,100 & 0,100 \\
\hline Mistura mineral $^{2}$ & 0,050 & 0,050 & 0,050 & 0,050 & 0,050 \\
\hline Antioxidante $^{3}$ & 0,010 & 0,010 & 0,010 & 0,010 & 0,010 \\
\hline DL- metionina (99\%) & 0,404 & 0,404 & 0,404 & 0,404 & 0,404 \\
\hline L-lisina $\mathrm{HCl}(78 \%)$ & 0,232 & 0,232 & 0,232 & 0,232 & 0,232 \\
\hline L-triptofano (98\%) & 0,083 & 0,083 & 0,083 & 0,083 & 0,083 \\
\hline L-valina $(98 \%)$ & 0,166 & 0,166 & 0,166 & 0,166 & 0,166 \\
\hline L-isoleucina (99\%) & 0,081 & 0,081 & 0,081 & 0,081 & 0,081 \\
\hline L-treonina $(98 \%)$ & 0,000 & 0,060 & 0,119 & 0,178 & 0,237 \\
\hline L-glutâmico (99\%) & 0,395 & 0,312 & 0,231 & 0,150 & 0,068 \\
\hline Inerte $^{4}$ & 0,005 & 0,028 & 0,050 & 0,072 & 0,095 \\
\hline Total & 100,000 & 100,000 & 100,000 & 100,000 & 100,000 \\
\hline \multicolumn{6}{|l|}{ Composição nutricional calculada } \\
\hline Proteína bruta $(\%)$ & 14,260 & 14,260 & 14,260 & 14,260 & 14,260 \\
\hline Energia metabolizável (kcal/Kg) & 2.900 & 2.900 & 2.900 & 2.900 & 2.900 \\
\hline Cálcio (\%) & 4,232 & 4,232 & 4,232 & 4,232 & 4,232 \\
\hline Fósforo disponível (\%) & 0,316 & 0,316 & 0,316 & 0,316 & 0,316 \\
\hline Sódio $(\%)$ & 0,237 & 0,237 & 0,237 & 0,237 & 0,237 \\
\hline Potássio (\%) & 0,611 & 0,611 & 0,611 & 0,611 & 0,611 \\
\hline Arginina digestível (\%) & 0,796 & 0,796 & 0,796 & 0,796 & 0,796 \\
\hline Lisina digestível (\%) & 0,768 & 0,768 & 0,768 & 0,768 & 0,768 \\
\hline Metionina + cistina digestível (\%) & 0,791 & 0,791 & 0,791 & 0,791 & 0,791 \\
\hline Fenilalanina + tirosina digestível (\%) & 1,055 & 1,055 & 1,055 & 1,055 & 1,055 \\
\hline Histidina digestível (\%) & 0,340 & 0,340 & 0,340 & 0,340 & 0,340 \\
\hline Glicina + serina digestível (\%) & 1,111 & 1,111 & 1,111 & 1,111 & 1,111 \\
\hline Leucina digestível (\%) & 1,168 & 1,168 & 1,168 & 1,168 & 1,168 \\
\hline Isoleucina digestível (\%) & 0,584 & 0,584 & 0,584 & 0,584 & 0,584 \\
\hline Treonina digestível (\%) & 0,461 & 0,515 & 0,569 & 0,622 & 0,676 \\
\hline Triptofano digestível (\%) & 0,215 & 0,215 & 0,215 & 0,215 & 0,215 \\
\hline Valina digestível (\%) & 0,737 & 0,737 & 0,737 & 0,737 & 0,737 \\
\hline Balanço eletrolítico da dieta $(\mathrm{mEq} / \mathrm{kg})^{5}$ & 146,765 & 146,765 & 146,765 & 146,765 & 146,765 \\
\hline
\end{tabular}

${ }^{1}$ Suplemento vitamínico - Composição/kg: vit. A - 7.200.000 U.I., vit. $\mathrm{D}_{3}-1.600 .000$ U.I., vit. E - 5.000 $\mathrm{mg}$, vit. $\mathrm{B}_{1}-900 \mathrm{mg}$, vit. $\mathrm{B}_{2}-2.700 \mathrm{mg}$, vit. $\mathrm{B}_{6}-1.500 \mathrm{mg}$, vit. $\mathrm{B}_{12}-7.200 \mathrm{mg}$, ác. pantotênico -5.900 $\mathrm{mg}$, vit. $\mathrm{K}_{3}-1.100 \mathrm{mg}$, ác. fólico $-250 \mathrm{mg}$, niacina $-16.200 \mathrm{mg}$, selênio $-250 \mathrm{mg}$, aditivo antioxidante - $250 \mathrm{mg}$; ${ }^{2}$ Suplemento mineral - Composição/kg: manganês $-100.000 \mathrm{mg}$, ferro - $60.000 \mathrm{mg}$, zinco $800.000 \mathrm{mg}$, cobre $-12.000 \mathrm{mg}$, iodo $-1.000 \mathrm{mg}$, selênio $-300 \mathrm{mg}$; ${ }^{3}$ Hidroxitolueno butilado (BHT); ${ }^{4}$ Areia. 
A eficiência de utilização da lisina por massa de ovos e a eficiência de utilização da lisina por números de ovos produzidos foram calculadas, respectivamente, a partir da massa dos ovos e do número de ovos produzidos por ave em razão do consumo de lisina digestível em gramas.

O peso médio dos ovos foi obtido com base na média dos pesos dos ovos coletados nos últimos cinco dias de cada subperíodo. A produção de massa de ovos foi obtida através da multiplicação da taxa de postura pelo peso médio dos ovos dividido por 100 .

As conversões alimentares por massa e por dúzias de ovos produzidos foram calculadas, respectivamente, a partir da massa dos ovos e do número de dúzias de ovos produzidos por ave em razão do consumo de ração.

Os pesos médios da casca, gema e albúmen foram calculados com base em uma amostra de 24 ovos de cada unidade experimental. Os ovos amostrais foram obtidos da coleta diária de dois ovos com o peso médio da respectiva unidade experimental, durante os três últimos dias de cada subperíodo, totalizando seis ovos por subperíodo.

Os ovos amostrais foram pesados, quebrados e tiveram seus componentes separados. As gemas foram pesadas após a quebra dos ovos. As cascas foram lavadas, deixadas secar na sombra por três dias e depois foram pesadas. $\mathrm{O}$ peso do albúmen foi obtido pela diferença entre o peso do ovo e o peso da gema mais o peso da casca. As aves foram pesadas no início e no final do experimento e, pela diferença entre as pesagens, foi obtido o ganho de peso médio.

O balanço de nitrogênio foi realizado com base no método de coleta total das excretas. Durantes três dias, na $58^{\mathrm{a}}$ semana de idade das poedeiras, foram coletadas as excretas das aves de quatro repetições de cada tratamento. As excretas foram armazenadas em freezer para posterior análise da excreção de nitrogênio. Utilizou o método de Kjeldahl para a determinação do teor de nitrogênio na excreta e nas dietas experimentais. $\mathrm{O}$ balanço de nitrogênio determinado com base na matéria seca foi dado em porcentagem, levando em consideração o total de nitrogênio retido pela ave sobre o total ingerido.

A relação ideal treonina:lisina digestíveis foi estimado com base nos dados obtidos das variáveis analisadas, utilizando o programa computacional Statistical Analisys System (SAS). Considerou-se o nível de significância de 0,05 .

\section{RESULTADO E DISCUSSÃO}

Durante o período experimental as médias das temperaturas mínimas e máximas do ar aferidas e registradas no interior do galpão foram de $14 \pm 2 \mathrm{e}$ $27 \pm 2^{\circ} \mathrm{C}$, respectivamente. $\mathrm{O}$ intervalo de temperatura considerado como confortável pelo manual das aves utilizadas é de 18 a $25^{\circ} \mathrm{C}$ (HY LINE W36, 2015). Portanto, pode-se inferir que as aves deste estudo foram expostas a períodos de estresse térmico moderado.

Não houve efeito significativo $(\mathrm{P}>0,05)$ das relações treonina:lisina digestíveis sobre o desempenho produtivo das galinhas poedeiras leves no período de 42 a 58 semanas de idade, exceto para o consumo de treonina (Tabela 2).

As relações treonina:lisina digestíveis na dieta não influenciaram $(\mathrm{P}>0,05)$ a taxa de postura das galinhas poedeiras no período de 42 a 58 semanas de idade, que apresentaram média de 83,91\%. Contudo, essa taxa de postura é inferior 
ao citado pelo manual da marca comercial para a mesma idade, que é de 88,5\% (HY LINE W36, 2015).

É importante ressaltar que as dietas experimentais foram formuladas com valores subestimados da exigência de lisina digestível $(0,768 \%)$ para garantir que toda lisina consumida fosse usada. Possivelmente, a menor concentração de lisina digestível na ração limitou o pico de postura das aves, resultando na menor taxa média de postura das aves.

Rocha (2010) também não observou efeito das relações treonina:lisina digestíveis estudadas (65 a 90\%) sobre a taxa de postura de poedeiras leves de 42 a 58 semanas de idade. Este pesquisador utilizou o nível subestimado de lisina digestível $(0,730 \%)$ e encontrou taxa de postura média das aves de $82 \%$.

Tabela 2. Desempenho produtivo e balanço de nitrogênio de poedeiras leves de 42 a 58 semanas de idade alimentadas com relações treonina:lisina digestíveis

\begin{tabular}{|c|c|c|c|c|c|c|c|}
\hline \multirow{2}{*}{ Variáveis } & \multicolumn{5}{|c|}{ Relações treonina:lisina digestíveis (\%) } & \multirow{2}{*}{$\begin{array}{l}\text { CV } \\
(\%)\end{array}$} & \multirow{2}{*}{ P-valor } \\
\hline & 60 & 67 & 74 & 81 & 88 & & \\
\hline Taxa de postura (\%) & 83,72 & 84,66 & 84,45 & 83,71 & 83,01 & 3,47 & 0,80 \\
\hline Consumo de ração (g/ave/dia) & 96,86 & 95,06 & 96,62 & 96,45 & 94,42 & 2,38 & 0,16 \\
\hline Consumo de lisina (mg/ave/dia) & 743,91 & 730,09 & 742,06 & 740,73 & 725,15 & 2,38 & 0,16 \\
\hline $\begin{array}{l}\text { Consumo de treonina } \\
(\mathrm{mg} / \mathrm{ave} / \mathrm{dia})^{1}\end{array}$ & 446,54 & 489,58 & 549,78 & 599,91 & 638,28 & 2,49 & $<0,001$ \\
\hline $\begin{array}{l}\text { Eficiência de utilização de lisina } \\
\text { por massa de ovos }(\mathrm{g} / \mathrm{g})\end{array}$ & 71,26 & 72,74 & 72,26 & 71,15 & 71,21 & 2,80 & 0,39 \\
\hline $\begin{array}{l}\text { Eficiência de utilização de lisina } \\
\text { por produção de ovos ( }{ }^{\circ} \\
\text { ovos/g) }\end{array}$ & 1,12 & 1,16 & 1,14 & 1,13 & 1,14 & 3,06 & 0,34 \\
\hline Peso dos Ovos (g) & 63,34 & 62,73 & 63,46 & 62,94 & 62,19 & 2,24 & 0,40 \\
\hline Massa de Ovos (g/ave/dia) & 53,02 & 53,13 & 53,60 & 52,68 & 51,63 & 3,39 & 0,27 \\
\hline Conversão alimentar (kg/dz) & 1,39 & 1,35 & 1,38 & 1,39 & 1,37 & 3,14 & 0,40 \\
\hline Conversão alimentar (kg/kg) & 1,83 & 1,79 & 1,81 & 1,83 & 1,84 & 2,85 & 0,41 \\
\hline Peso corporal final (kg/ave) & 1,44 & 1,44 & 1,47 & 1,47 & 1,46 & 5,46 & 0,88 \\
\hline Ganho de peso corporal (g/ave) & $-0,03$ & $-0,02$ & 0,01 & 0,02 & $-0,03$ & 33,58 & 0,14 \\
\hline Balanço de nitrogênio (\%) & 48,92 & 55,93 & 54,47 & 51,11 & 54,79 & 9,19 & 0,27 \\
\hline
\end{tabular}

$\mathrm{CV}=$ coeficiente de variação; ${ }^{\mathrm{E}}$ Efeito Linear.

De forma semelhante, Agustini et al. (2014) trabalhando com poedeiras semipesadas de 50 a 66 semanas de idade, também não observaram efeito na taxa de postura, determinando que a relação treonina:lisina digestíveis de $63 \%$, correspondente ao consumo de $516 \mathrm{mg} /$ ave/dia, foi suficiente para essa variável.

Por outro lado, Lelis (2010) verificou maior produção de ovos com a relação treonina:lisina digestíveis de $72 \%$ e nível de lisina de $0,66 \%$, para poedeiras semipesadas de 42 a 54 semanas de idade.

O consumo médio de ração foi de $95 \mathrm{~g} /$ ave/dia, valor equivalente àquele usado para a formulação das dietas experimentais e ao consumo médio sugerido pelo manual da marca comercial (HY LINE W36, 2015), que é de 96g para a idade avaliada. Portanto, os períodos de estresse térmico em que as aves foram expostas não foram suficientes para afetar o consumo de ração. 
Não foi verificado efeito das relações treonina:lisina digestíveis $(\mathrm{P}>0,05)$ para consumo de ração e consumo de lisina. A manutenção no consumo de ração pode ser explicada pela teoria proposta por Martínez-Amescua et al. (1999), em que as galinhas poedeiras podem ser incapazes de compensar a deficiência de treonina através do aumento do consumo de ração. E o consumo de lisina foi equivalente entre os tratamentos porque $o$ nível desse aminoácido não variou nas rações experimentais e não houve alteração no consumo de ração.

O resultado obtido para consumo de ração está de acordos com Sá et al. (2007), Matos et al. (2009a) e Lelis (2010) que também não encontraram efeito das relações treonina:lisina digestíveis sobre o consumo de ração das poedeiras comerciais.

Houve efeito significativo das relações treonina:lisina digestíveis $(\mathrm{P}<0,05)$ para $\mathrm{o}$ consumo de treonina (Tabela 2). Verificou-se efeito linear conforme a equação: $\hat{Y}=21,9573+919,56 x, r^{2}=$ 99,50, para consumo de treonina de acordo com o aumento das relações treonina:lisina digestíveis na dieta. Esse resultado está diretamente relacionado com a concentração de treonina na dieta, visto que o consumo de ração não variou em função das relações treonina:lisina digestíveis avaliadas.

Não foi observado efeito das relações treonina:lisina digestíveis $(\mathrm{P}>0,05)$ sobre a eficiência de utilização da lisina, tanto por massa quanto por número de ovos produzidos (Tabela 2). Isso significa que as poedeiras dos diferentes tratamentos utilizaram estatisticamente a mesma quantidade de lisina para produzir um grama de massa de ovo ou um ovo.

As relações treonina:lisina digestíveis não influenciaram $(\mathrm{P}>0,05)$ o peso médio dos ovos, massa dos ovos e conversões alimentares (Tabela 2). Dessa forma, o consumo de ração com relação treonina:lisina digestíveis de $60 \%$, correspondendo ao consumo de $446 \mathrm{mg} / \mathrm{ave} / \mathrm{dia}$ de treonina pelas aves foi suficiente para atender essas variáveis.

Em estudos com poedeiras leves de 42 a 58 semanas de idade, Rocha (2010), também não verificou efeito significativo das relações treonina:lisina digestíveis sobre o peso médio dos ovos, massa de ovos e conversões alimentares, embora o consumo de treonina tenha sido superior (467mg/ave/dia) ao deste estudo (446mg/ave/dia). Agustini et al. (2014) também não encontraram diferença significativa para peso médio dos ovos, massa de ovos e conversão por massa de ovos, entretanto, observaram melhor conversão por dúzia de ovos com o nível de $0,521 \%$ de treonina digestível na ração, correspondente à relação treonina:lisina digestíveis de $69 \%$ ao trabalhar com poedeiras semipesadas de 50 a 66 semanas de idade.

Os resultados encontrados para peso médio dos ovos, massa de ovos e conversões alimentares diferem daqueles obtidos por Abdel-Wareth et al. (2014), que observaram que a relação treonina:lisina digestíveis de $49 \%$ resultou em menor peso e massa de ovos e pior conversão alimentar das poedeiras Hy Line Brown de 68 a 76 semanas de idade. Todavia, o consumo de treonina determinado na referida relação foi de $448 \mathrm{mg} /$ ave/dia, valor próximo ao verificado neste estudo que foi de 446mg/ave/dia, com a relação treonina:lisina digestíveis de $60 \%$, em que não foi observado o efeito negativo sobre essas varáveis.

Lelis (2010) não verificou diferença no peso dos ovos, mas observou maior produção de massa de ovos e melhores conversões alimentares para poedeiras semipesadas de 42 a 54 semanas de idade consumindo ração com o nível de $0,475 \%$ de treonina, correspondente à relação treonina:lisina digestíveis de $72 \%$. 
Não houve efeito significativo das relações treonina:lisina digestíveis $(\mathrm{P}>0,05)$ sobre o ganho de peso das aves e peso corporal final. Este resultado está condizente com os observados por Sá et al. (2007), que não observaram variação significativa no peso das poedeiras leves e semipesadas, entre a $34^{\mathrm{a}}$ e $50^{\mathrm{a}}$ semanas de idade, alimentadas com rações contendo níveis de treonina digestível variando entre 0,41 e $0,55 \%$.

As relações treonina:lisina digestíveis não influenciaram $(\mathrm{P}>0,05)$ o balanço de nitrogênio (Tabela 2). Resultados similares foram observados por Matos et al. (2009b), que também não observaram variação no balanço de nitrogênio em função dos níveis de treonina $(0,50 ; 0,55$ e $0,60 \%$ ) na ração de poedeiras leves de 44 a 50 semanas de idade.
Considerando que as dietas experimentais foram formuladas para conter o mesmo nível de proteína bruta, pode-se inferir que, conforme Vasconcellos et al. (2011) verificaram, existe uma correlação positiva entre o nível de proteína bruta da ração e o balanço de nitrogênio.

Os pesos e porcentagens da casca, do albúmen e da gema não foram influenciados $(\mathrm{P}>0,05)$ pelas relações treonina:lisina digestíveis da dieta (Tabela $3)$. Este resultado está condizente com o peso dos ovos observado neste estudo. Portanto, a relação treonina:lisina digestíveis de $60 \%$, correspondente ao consumo de $446 \mathrm{mg} / \mathrm{ave} / \mathrm{dia}$ de treonina digestível é suficiente para manter a qualidade dos ovos.

Tabela 3. Qualidade dos ovos de galinhas poedeiras leves de 42 a 58 semanas de idade alimentadas com relações treonina:lisina digestíveis

\begin{tabular}{lccccccc}
\hline \multirow{2}{*}{ Variáveis } & \multicolumn{9}{c}{ Relações treonina:lisina digestíveis (\%) } & \multirow{2}{*}{ CV (\%) } & \multirow{2}{*}{ P-valor } \\
\cline { 2 - 5 } & 60 & 67 & 74 & 81 & 88 & & \\
\hline Albúmen (g) & 40,58 & 40,89 & 40,68 & 40,36 & 40,19 & 2,45 & 0,67 \\
Gema (g) & 17,54 & 17,34 & 17,73 & 17,65 & 17,50 & 2,58 & 0,48 \\
Casca (g) & 5,86 & 5,89 & 5,82 & 5,78 & 5,87 & 2,93 & 0,68 \\
Albúmen (\%) & 63,42 & 63,77 & 63,33 & 63,45 & 63,23 & 1,13 & 0,64 \\
Gema (\%) & 27,26 & 26,61 & 27,17 & 27,31 & 27,39 & 2,47 & 0,17 \\
Casca (\%) & 9,17 & 9,18 & 9,06 & 9,08 & 9,23 & 2,70 & 0,61 \\
\hline
\end{tabular}

$\mathrm{CV}=$ coeficiente de variação.

Em estudo com poedeiras semipesadas de 50 a 66 semanas de idade, Agustini et al. (2014) não observaram influência dos níveis de treonina sobre a porcentagem da gema e da casca dos ovos, mas observaram que a porcentagem do albúmen se estabilizou em $63 \%$ a partir do nível de inclusão de 0,487\%, correspondente à relação treonina:lisina digestíveis de $65 \%$. Contudo, neste estudo o nível de $0,461 \%$ de treonina na ração, correspondente à relação treonina:lisina digestíveis de $60 \%$, foi suficiente para estabilizar a porcentagem de albúmen em $63 \%$.

Os resultados obtidos para as variáveis de qualidade do ovo estão de acordo com aqueles encontrados por Rocha et al. (2010) e Lelis (2010). Embora Bregendahl et al. (2008) também não tenham observado efeito sobre 0 conteúdo da casca do ovo, os conteúdos da gema e do albúmen foram influenciados de forma positiva pela inclusão de treonina na ração. 
Rev. Bras. Saúde Prod. Anim., Salvador, v.17, n.3, p.438-447 jul./set., $2016 \quad \underline{\text { http://www.rbspa.ufba.br }}$ ISSN 15199940

Assim, concluí-se que a relação treonina:lisina digestíveis de $60 \%$ é suficiente para manter a produção e qualidade dos ovos de poedeiras leves de 42 a 58 semanas de idade, que corresponde ao nível de $0,461 \%$ de treonina digestível na ração e ao consumo diário de treonina de $446 \mathrm{mg} /$ ave.

\section{AGRADECIMENTOS}

Ao Conselho Nacional de Desenvolvimento Científico Tecnológico (CNPq) pelo apoio financeiro e à Ajinomoto do Brasil Indústria e Comércio de Alimentos Ltda pela doação dos aminoácidos.

\section{REFERÊNCIAS}

ABDEL-WARETH, A.A.A.; ESMAIL, Z.S.H. Some productive, egg quality and serum metabolic profile responses due to L-theonine supplementation to laying hens diets. Asian Journal of Poultry Science, v.8, n.3, p.75-81, 2014.

AGUSTINI, M.A.B.; NUNES, R.V.;VILELA, C.G. TAKAHASHI, S. E.; VILELA, V. O.; BUENO, R. S.; POLESE, C. Níveis nutricionais de treonina digestível para poedeiras semipesadas de 75 a 90 semanas de idade. Semina: Ciências Agrárias, v.35, n.6, p.3449-3456, 2014.

\section{ALMEIDA, R.L. Relações valina:lisina em rações para poedeiras leves de 24 a 58 semanas de idade. 2014. 75f. Tese (Doutorado em Zootecnia) - Universidade Federal de Viçosa, Viçosa.}

BREGENDAHL, K.; ROBERTS, S.A.; KERR, B.; HOEHLER, D. Ideal Ratios of Isoleucine, Methionine, Methionine Plus Cystine, Threonine, Tryptophan, and Valine Relative to Lysine for White Leghorn-Type Laying Hens of TwentyEight to Thirty-Four Weeks of Age.

Poultry Science, v.87, n.4, p.744-758, 2008.

BRUMANO, G.; GOMES, P.C.; DONZELE, J.L.; ROSTAGNO, H.S.; ROCHA, T. C.; ALMEIDA, R. L. Níveis de metionina+cistina digestível em rações para poedeiras leves no período de 24 a 40 semanas de idade.

Revista Brasileira de Zootecnia, v.39, n.6, p.1228-1236, 2010

CALDERANO, A.A.; GOMES, P.C.; DONZELE, J.L.; BARRETO, S.L.T.; VELLASCO, C.R.; MELLO, H.H.C.; LELIS, G.R.; ROCHA, T.C. Digestible tryptophan:digestible lysine ratio in diets for laying hens from 24 to 40 weeks of age. Revista Brasileira de Zootecnia, v.41, n.10, p.2176-2182, 2012.

HY-LINE DO BRASIL. Management Guide: W-36 commercial layers. S.I.: s.n., 2015. 44p.

LELIS, G.R. Atualização da proteína ideal para poedeiras semipesadas: treonina e valina. 2010. 98f. Tese (Doutorado em Zootecnia) Universidade Federal de Viçosa, Viçosa.

MARTINEZ-AMEZCUA, C.; LAPARRA-VEJA, J.L.; AVILAGONZALES, FUENTE, E.B.; JINEZ, T.; KIDD, M.T. Dietary Lthreonine responses in laying hens. Journal Applied Poultry Research, v.8, n.2, p.236-241, 1999. 
Rev. Bras. Saúde Prod. Anim., Salvador, v.17, n.3, p.438-447 jul./set., $2016 \quad \underline{\text { http://www.rbspa.ufba.br }}$

MATOS, M. S.; LEANDRO, N.S.M.; STRINGHINI, J.H.; CAFÉ, B.M.; CARVALHO, F.B.; GOMES, N.A.

Níveis de lisina e treonina para poedeiras comerciais Lohmann LSL de 24 a 44 semanas de idade. Acta Scientiarum Animal Science, v.31, n.1, p.19-24, 2009a.

MATOS, M.S.; LEANDRO, N.S.M.; CARVALHO, F.B.; STRINGHINI, J.H.; CAFÉ, B.M.; LOPES, K.L. Níveis de lisina e treonina digestíveis na ração de poedeiras comerciais sobre a qualidade de ovos. Acta Scientiarum Animal Science, v.31, n.1, p.25-29, 2009b.

MELLO, H.H.C.; GOMES, P.C.; ROCHA, T.C. DONZELE, J.L.; ALMEIDA, R.L.; TRONI, A.R.; CARVALHO, B.R.; VIANA, G.S. Determination of digestible isoleucine:lysine ratio in diets for laying hens aged 42-58 weeks. Revista

Brasileira de Zootecnia, v.41, n.5, p.1313-1317, 2012.

ROCHA, T.C. Relações treonina:lisina em rações para poedeiras leves no período de produção. 2010. 64f. Tese (Doutorado em Zootecnia) - Universidade Federal de Viçosa, Viçosa.

ROSTAGNO, H.S.; ALBINO, L.F.T.; DONZELE, J.L. GOMES, P.C.; OLIVEIRA, R. F.; LOPES, D. C.; FERREIRA, A. S.; BARRETO, S. L. T.; EUCLIDES, R. F. Tabelas brasileiras para aves e suínos: Composição de alimentos e exigências nutricionais. 3 ed. Viçosa: Universidade Federal de Viçosa, 2011. 252p.
SÁ, L.M.; GOMES. P.C.; CECON, P.R.; ROSTAGNO, H.S.;

D'AGOSTINI, P. Exigência nutricional de treonina digestível para galinhas poedeiras no período de 34 a 50 semanas de idade. Revista Brasileira de Zootecnia, v.36, n.6, p.1846-1853, 2007.

VASCONCELLOS, C.H.F.; FONTES, D.O.; LARA, L.J.C.; VIDAL, T.Z.B.; SILVA, M.A.; SILVA, P.C.

Determinação da energia metabolizável e balanço de nitrogênio de dietas com diferentes teores de proteína bruta para frangos de corte. Arquivo Brasileiro de Medicina Veterinária e Zootecnia, v.63, n.3, p.659-669, 2011.

Data de recebimento: 25/06/2015

Data de aprovação: 02/08/2016 